\title{
DISCRICIONARIEDADE JUDICIAL E A INDETERMINABILIDADE DOS PRINCÍPIOS: POR UMA PERCEPÇÃO DE PRINCÍPIOS PARA ALÉM DAS OTIMIZAÇÕES
}

\section{JUDICIAL DISCRETION AND THE INDETERMINABILITY OF PRINCIPLES: FOR A PERCEPTION OF PRINCIPLES BEYOND OPTIMIZATIONS}

\author{
Hamilton da Cunha Iribure Júnior ${ }^{1}$ \\ Gustavo Silva Xavier ${ }^{2}$
}

\section{RESUMO}

Este artigo tem como escopo a problematização do conceito e da proliferação dos princípios utilizados na prática jurídica brasileira para, a partir disso, discutir seu papel na redução dos espaços de discricionariedade judicial. Para tanto, percorre-se o seguinte itinerário: a) inicia-se com o célere debate entre Dworkin e Hart, demonstrando suas implicações; b) em um segundo momento, analisa-se a teoria dos princípios de Robert Alexy para, em seguida, confrontá-la com a teoria política de Ronald Dworkin; c) com base na obra de Rafael Thomas de Oliveira, apresentam-se os conceitos distintos que podem ser dados ao conceito de princípio, tais como i) princípios gerais do direito; ii) princípios jurídico-epistemológicos; iii) princípios pragmáticos-problemáticos, confrontando os primeiros com os princípios constitucionais; d) posteriormente, analisa o problema do panprincipiologismo; e) por fim, apresenta a institucionalização do mundo prático pelos princípios na Crítica Hermenêutica do Direito de Lenio Streck. Para serem alcançados tais objetivos, utilizam-se os aportes teóricos da Crítica Hermenêutica do Direito de Lenio Streck. Conclui-se que princípios (constitucionais) apresentam espaços argumentativos que permitem o controle das decisões judiciais, que retiram seu conteúdo normativo de uma vivência intersubjetiva emanada dos vínculos existentes na moralidade política da comunidade, sendo, pois, faticizados (vivenciados) pelos participantes da comunidade.

Palavras-chave: Discricionariedade. Princípios. Panprincipiologismo. Crítica hermenêutica do direito.

\footnotetext{
${ }^{1}$ Doutor e Mestre em Direito pela PUC/SP. Professor do Mestrado e da Graduação da Faculdade de Direito do Sul de Minas (FDSM). Advogado. Faculdade de Direito do Sul de Minas (FDSM). Minas Gerais. Lattes: http://lattes.cnpq.br/9009611714454221 ORCID: http://orcid.org/0000-0002-0036-3587 E-mail: hamilton.adv@terra.com.br

${ }^{2}$ Mestre em Direito pela Faculdade de Direito do Sul de Minas. Professor no Centro Universitário de Itajubá e em Pós-graduações. Procurador Legislativo da Câmara Municipal de Borda da Mata/MG. Advogado. Centro Universitário de Itajubá (FEPI). Minas Gerais. Lattes: http://lattes.cnpq.br/9488087504267525 ORCID: https://orcid.org/0000-0002-1304-3523 E-mail: gustavoadv.fdsm@gmail.com
} 


\begin{abstract}
The present article has as its scope the problematization of the definition and the proliferation of the usage of principles in the Brazilian judicial practice to discuss, through that, its role in the reduction of judicial discretionary spaces. To this end, the following itinerary is followed: a) starting from the classical debate between Dworkin and Hart, showing its implications; b) secondly, an analysis of Robert Alexy's theory to confront it with Ronald Dworkin political theory; c) based on the work of Rafael Thomas de Oliveira, to present the separated concepts for what a principle can be, such as i) general principles of law; ii) legal-epistemic principles; iii) pragmatic-problematic principles, confronting the first with constitutional principles; d) later on, to conduct an analysis of the problem of the panprincipiologism; e) finally, to present the institutionalization of the practical world based on the principles of the Critical Hermeneutics of Law by Lenio Streck. To that end, the theoretical basis from Lenio Streck's Critical Hermeneutics of Law is used. It is hypothesized that (constitutional) principles create argumentative spaces that allow for the control of judicial decisions, that remove its normative content from a intersubjective experience that emanated from the linkages that exist in the political morality of the community and are, thus, facticized (lived) by the members of said community.
\end{abstract}

Keywords: Discretionary adjudication. Principles. Panprincipiologism. Critical hermeneutics of law.

\title{
INTRODUÇÃO
}

Em tempos de pós-positivismo, em que o direito passa a assumir um papel de destaque, mormente pelo advento de Constituições compromissórias que visam transformar a realidade social, bem como pela importância que vem ganhando as decisões dos Tribunais Superiores, faz-se necessário discutir as condições de possibilidade de aplicação do direito em tempos de protagonismo judicial. Nesse desiderato, os pontos colocados por Herbert Hart (2009) no posfácio de seu célere $O$ Conceito de Direito, em resposta a alguns questionamentos de Dworkin, têm aspectos importantes que nos interessam sobremaneira: o papel dos princípios como modo de enfrentamento da discricionariedade judicial.

Não obstante os livros de direito tragam alguma definição acerca do conceito de princípio - juntamente com um rol com vários princípios - fato é que não há uma definição unânime do que sejam os princípios e de sua importância para a obtenção de decisões adequadas à Constituição. Virgilio Afonso da Silva (2003, p. 612) aduz que, apesar das diversas classificações atinentes aos princípios e que muitas vezes se apresentam como conflitantes, há uma ideia que costuma ser a mesma: a de que os princípios são normas fundamentais de um 
sistema, enquanto as regras seriam a concretização destes e teriam caráter mais instrumental e menos fundamental. Todavia, há uma falta de clareza do que seja um princípio e seu uso na prática jurídica parece conduzir a uma pluralidade de significados.

No Brasil, tornou-se comum a menção na prática jurídica dos Tribunais e na doutrina ${ }^{3}$ de que os princípios são mandados de otimização que comportam um sopesamento, uma vez que podem ser cumpridos em diferentes graus, cujo marco teórico advém da teoria dos princípios de Robert Alexy, mas cujos pressupostos não são seguidos à risca no cotidiano forense ${ }^{4}$. Além disso, a pluralidade de definições acerca do conceito de princípio, a ideia de que este apresenta uma abertura interpretativa e a não ruptura com a ideia de que os princípios constitucionais não são sucedâneos dos princípios gerais do direito, fazem com que haja o uso desenfreado dos princípios na prática jurídica brasileira, fenômeno denominado por Lenio Streck $(2012$; 2014a) de "panprincipiologismo", que permite a qualquer decisão ser adequada, já que bastaria ao intérprete lançar mão da ampla gama principiológica para o caso passar a ser dotado de autoridade.

Nessa esteira, este artigo tem por escopo investigar o entendimento dominante na doutrina e na jurisprudência acerca da utilização dos princípios nas decisões judiciais e qual o seu papel na redução dos espaços de discricionariedade judicial. Para tanto, percorrerá o seguinte itinerário: a) iniciará com o célere debate entre Dworkin e Hart, demonstrando suas implicações; b) em um segundo momento, analisará a teoria dos princípios de Robert Alexy para, em seguida, confrontá-la com a teoria política de Ronald Dworkin; c) com base na obra de Rafael Thomas de Oliveira (2008), apresenta os conceitos distintos que podem ser dados ao conceito de princípio, tais como i) princípios gerais do direito; ii) princípios jurídicoepistemológicos; iii) princípios pragmáticos-problemáticos, confrontando os primeiros com os princípios constitucionais; d) posteriormente, abordará o problema do "panprincipiologismo"; e) por fim, apresentará a importância dada aos princípios (constitucionais) na Crítica Hermenêutica do Direito de Lenio Streck.

\footnotetext{
${ }^{3}$ Não obstante os trabalhos de Ronald Dworkin e Robert Alexy acerca dos princípios sejam os mais difundidos e conhecidos no Brasil, a Teoria dos Princípios de Ávila (2008) encontra grande menção e aceitação nos manuais de direito brasileiros (Cf. DIDIER, 2015, p. 48; LOPES JR, 2014, p. 155). Além de uma concepção própria de diferenciação entre princípios e regras, também há em Ávila um meio de superação de normas que veio a denominar de derrotabilidade (Cf. ÁVILA, 2008, p. 64-78).

${ }^{4}$ Fausto de Moraes (2014), Prêmio Capes 2014, sob orientação de LenioStreck, demonstrou em sua tese de doutorado que o Supremo Tribunal Federal, nas quase duzentas vezes em que lançou mão da ponderação, em nenhum dos casos o fez nos moldes propostos por Robert Alexy.
} 
Para se alcançar os objetivos propostos, utiliza-se o método de pesquisa bibliográfica e documental, com a análise de obras jurídicas e julgados por parte dos Tribunais Superiores, valendo-se dos aportes teóricos da Crítica Hermenêutica de Lenio Streck. Assim, espera-se contribuir para a problematização do conceito de princípio e suas implicações práticas, de modo a reduzir sua utilização seletiva e os espaços de discricionariedade judicial na busca de respostas adequadas à Constituição.

\section{REVISITANDO O DEBATE DWORKIN/HART: OS PRINCÍPIOS COMO RESPOSTA À DISCRICIONARIEDADE JUDICIAL}

O conhecido debate entre Ronald Dworkin e seu antecessor em Oxford, Herbert Hart, inicia-se com o artigo daquele intitulado como - O Modelo de Regras I - publicado em 1967, que mais tarde (1977) foi republicado como constante do capítulo 2 de seu livro - Levando os Direitos a Sério - como uma crítica às teses centrais de Herbert Hart em sua obra principal $O$ Conceito de Direito ${ }^{5}$. Não nos ateremos a todos os argumentos utilizados, mas tão somente aos aportes necessários para demonstrar: i) a distinção entre princípios e regras utilizada por Dworkin e que serviu, mais tarde, como ponto de partida de Robert Alexy, um dos mais influentes jusfilósofos estrangeiros no Brasil; ii) o papel dos princípios (constitucionais) como resposta à discricionariedade judicial.

Dworkin é um grande crítico ${ }^{6}$ da teoria de Hart, colocando a obra do positivista no cerne de suas preocupações, mormente pelo fato de ser, à época, "a mais influente versão do positivismo (DWORKIN, 2002, p. XI)”. Com Dworkin (2002, p. 27-28), podem ser identificadas três características centrais do positivismo jurídico: a) o direito de uma comunidade se apresenta como um conjunto de regras utilizadas por ela com o intuito de determinar qual conduta será punida ou coagida; b) tal conjunto é coextensivo com o direito, haja vista que se o caso não estiver acobertado por uma regra, ele não poderá ser decidido pela aplicação do direito. Assim, na ausência de uma regra aplicável ao caso concreto, o mesmo deverá ser decidido por alguma autoridade pública, como o juiz, que exerce seu discernimento

\footnotetext{
${ }^{5}$ O último ponto sobre o debate veio no Pós-Escrito em 1994 em seu O Conceito de Direito, sendo que a tréplica de Dworkin adveio em 2004 no ensaio O Pós-Escrito de Hart e a Questão da Filosofia Política, cujo conteúdo consta do capítulo 06 de seu livro A Justiça de Toga (DWORKIN, 2010). Para um maior aprofundamento acerca do debate entre Dworkin e Hart e seus desdobramentos: Cf. SHAPIRO, 2007; MOTTA, 2017.

${ }^{6}$ Dworkin é um grande crítico do positivismo jurídico, chamando atenção a sua proposta de superação dessa concepção e do direito como interpretação de textos para uma concepção que adota o direito como uma prática interpretativa e que o considera como integridade em relação a princípios de moralidade política.
} 
pessoal; c) falar que alguém tem uma obrigação jurídica é dizer que seu caso se enquadra em alguma regra jurídica válida.

Nesse diapasão, Hart (2009, p. 91) sustentou que o direito é um sistema composto exclusivamente de regras - sendo que algumas impõem deveres, por dizer respeito a ações (regras primárias) e outras atribuem poderes e permitem a alteração ou criação das primeiras (regras secundárias). As últimas surgem pelas deficiências do sistema que não podem ser solucionadas pelas primárias. Isso porque as primeiras apresentam incerteza - já que não há como resolver dúvidas a respeito da existência de uma regra - e são estáticas, na medida em que não indicam o procedimento que permitiria a introdução de novas regras (MOTTA, 2017, p. 99).

Daí a importância, dentre as regras secundárias, das regras de reconhecimento em Hart, que seriam o fundamento de um sistema jurídico (HART, 2009, p. 129), mormente pela circunstância de oferecer às autoridades públicas os "critérios válidos para a identificação das normas primárias da obrigação" (HART, 2009, p. 130). Pode-se comparar, didaticamente, as regras de reconhecimento de Hart com a norma fundamental de Kelsen.

Nesse aspecto, Hart desenvolve a tese do direito como instituição social - como simples questão de fato - em que o verdadeiro argumento do direito é empírico e não teórico. Nesses termos, os deveres são criados por regras sociais que ganham normatividade por seu reconhecimento social (MOTTA, 2017, p. 58). Ademais, Hart (2009, p. 164) também observa que a linguagem expressa pelas regras não é precisa e pode gerar incertezas, o que confere ao intérprete discricionariedade (HART, 2009, p. 166). É o que se pode denominar de "textura aberta". Devido a sua indeterminação, a linguagem possibilitaria certo grau de incerteza ao intérprete, o que lhe possibilita solucionar o caso por meio de uma escolha. Em suma, como o juiz possui poder conferido pela regra de reconhecimento de proceder a uma escolha, caberá a ele decidir o caso concreto do modo que entender melhor.

É aqui que entra a importância do debate com Dworkin: ele reconhece que não apenas as regras são juridicamente vinculantes, mas também os princípios, que são um "padrão que deve ser observado, não porque vá promover ou assegurar uma situação econômica, política ou social considerada desejável, mas porque é uma exigência de justiça ou equidade ou alguma outra dimensão da moralidade" (DWORKIN, 2002, p. 35). Assim, Dworkin contrapõe Hart ao dizer que há outros fundamentos além das regras que são utilizados nos julgamentos e que também possuem força, ainda que nos casos denominados duvidosos. 
Enquanto para Hart os casos duvidosos ou que não apresentam uma solução prevista em uma regra devem ser solucionados pela discrição judicial - que cria direito novo - em Dworkin o juiz tem o dever de articular, pelos princípios, argumentos para a solução do caso concreto. Os princípios forneceriam as bases para a decisão judicial, que são a identificação das preocupações e tradições morais da comunidade que sustentam as regras (OLIVEIRA, 2008, p. 106).

Dworkin $^{7}$ observou também que, nos casos difíceis, os juízes recorriam às regras que não fazem parte do direito positivo. Para além das regras - que impõem direitos e obrigações (proíbem, permitem ou facultam algo) - os princípios seriam todos os demais padrões de moralidade política a que as decisões recorrem para decidir os casos que não são abrangidos pelas regras. São, pois, questões de peso (importância), já que conduzem a interpretação para certo caminho (SIMIONI, 2014, p. 335), sendo importantes para interpretação de todas as regras do direito.

Ao contrário de Alexy, que divide as normas apenas em princípios e regras, Dworkin observa que há duas espécies que são recorrentes nas decisões judiciais: a utilização de argumentos justificados por princípios morais e por objetivos políticos, denominados de policies. Assim, ao lado das regras e dos princípios, há também as diretrizes políticas. Enquanto estas dizem respeito a um objetivo a ser alcançado - buscando garantir ou promover alguma situação econômica -, os princípios (argumentos de direito) são argumentos em favor de algum direito, de modo que as decisões devem ser geradas por princípios e não por política.

Como se identifica, então, um princípio em Dworkin? Por meio de uma questão de argumentação: eles são padrões de moralidade política que fundamentam nossas práticas (SIMIONI, 2014, p. 339), que devem ser motivadas de acordo com a capacidade de justificação adequada de uma interpretação do direito.

Cremos que, em que pese a vastidão da obra de Dworkin e de seus desdobramentos, já se faz possível passarmos à análise do conceito de princípio (e seu papel) na teoria de um dos mais influentes jusfilósofos em território nacional.

\footnotetext{
${ }^{7}$ Um conhecido exemplo trazido por Dworkin (2002) diz respeito ao famoso caso Riggs contra Palmer julgado por um tribunal de Nova Iorque que decidiu sobre se um herdeiro nomeado em um testamento que teria atentado contra a vida de seu avô poderia receber uma herança: como a ninguém é dado o direito de "lucrar com sua própria fraude, beneficiar-se com seus próprios atos ilícitos, basear qualquer reivindicação na sua própria iniquidade ou adquirir bens em decorrência de seu próprio crime. O assassino não recebeu sua herança (DWORKIN, 2002, p. 37)". Assim, argumenta que a diferença entre princípios e regras é de natureza lógica, distinguindo-se quanto à natureza da orientação (caminho) que oferecem: enquanto as regras aplicam no âmbito do tudo ou nada, os princípios enunciam uma razão que conduz o argumento em certa direção (Ibidem, p. 39-40). Além disso, possuem uma dimensão que as regras não têm: de peso ou importância, de modo que aquele que for resolver o conflito deve levar em consideração a força relativa de cada um.
} 


\section{TEORIA DA ARGUMENTAÇÃO JURÍDICA DE ROBERT ALEXY}

A teoria dos princípios de Robert Alexy é uma das mais influentes na prática jurídica (e nos livros) no Brasil. Em pesquisa livre realizada no sítio eletrônico do Supremo Tribunal Federal (STF), pôde-se encontrar 62 acórdãos que fizeram menção ao seu nome, enquanto nomes como os de Dworkin apareceram 23, Habermas 08 e Luhmann 03 vezes, por exemplo, o que, em tese, demonstra que estes autores exercem menor influência nas decisões da Suprema Corte brasileira. Além da influência na prática jurídica brasileira, a teoria de Alexy também é adotada por grande parte dos juristas. Nesse diapasão, cite-se, por exemplo, a conceituação de Canotilho (1992, p. 1215) no sentido de que os princípios são "Normas que exigem a realização de algo, da melhor forma possível, de acordo com as possibilidades fácticas e jurídicas".

Se, por um lado, as obras de Alexy ganharam grande repercussão e destaque no território nacional, por outro, também não foram livres de críticas, como as objeções de Lenio Streck $(2013 ;$ 2014a) e de Habermas (2001), que serão brevemente expostas ao final deste tópico. Além disso, assim como em Dworkin e nos demais marcos teóricos que analisaremos brevemente neste artigo, não faremos uma exposição completa da obra de Alexy, mas sim de alguns pontos essenciais e que permitirão uma maior compreensão do entendimento majoritário acerca dos princípios (e de seu papel) no Brasil.

O ponto de partida de Alexy é a distinção teórica-estrutural das normas jurídicas em princípios e regras (ALEXY, 1997, p. 86-87). Como destaca Simioni (2014, p. 234), Alexy parte de uma distinção inspirada em Esser e Dworkin entre regras e princípios para que, a partir dela, possa fundamentar um procedimento racional de decisão para os casos considerados difíceis, nos quais o peso dado a um princípio de direito fundamental cede a outro, cuja aplicação é mais forte:

Toda a construção teórica de Alexy é, no fundo, uma tentativa de conciliar o positivismo normativo de Kelsen com o jusnaturalismo material de Radbruch, por meio de uma teoria procedimentalista da argumentação jurídica, no âmbito da qual a decisão jurídica pode encontrar tanto a sua justificação interna (validade normativa) quanto a sua justificação externa (correção moral). Tudo isso para garantir aracionalidadedas decisões judiciais (SIMIONI, 2014, p. 234-235).

Além disso, a teoria pura do Direito de Kelsen (2012), em seu capítulo oitavo, demonstrou que todo ato de interpretação produz indeterminações, o que faz com que haja problema de escolha de um dos sentidos da norma para a solução do caso concreto (SIMIONI, 2014, p. 236). A tentativa de racionalizar tal questão foi trabalhada pela teoria da argumentação 
jurídica, sendo criadas, então, uma série de distinções: casos fáceis e casos difíceis ${ }^{8}$, princípios $^{2}$ e regras, ponderação e subsunção, dentre outras.

Alexy (1997, p. 87) afirma que a distinção entre princípios e regras é uma distinção entre duas espécies de norma jurídica. Ambas dizem respeito ao dever-ser e podem ser formuladas por expressões deônticas do dever, da permissão e da proibição. Mas ao contrário de Dworkin - para quem as regras são normas positivadas ${ }^{9}$ nos textos e princípios são questões de moralidade política que justificam as primeiras - em Alexy tanto as regras quanto os princípios são questões de positividade (SIMIONI, 2014, p. 274). Mas como distingui-los? Para isso, são criados vários critérios.

Quanto ao critério da generalidade, enquanto os princípios são normas com elevado grau de abstração e generalidade, as regras apresentam baixo grau de abstração e generalidade, podendo ser mais facilmente identificáveis. Isso porque, quanto mais aberta for, mais caráter de princípio ela terá; por outro lado, quanto mais fechada for, mais o caráter de regra ela terá. Nesse diapasão, uma norma que fala a respeito da boa-fé seria um princípio, ao passo que aquela que fala sobre a idade limite para ingresso nas forças armadas seria uma regra.

No entanto, dentre outros critérios de distinção apresentados por Alexy, o que mais se destaca é o atinente à diferença qualitativa (a denominada tese forte). Com efeito, o ponto decisivo apresenta os princípios como normas que ordenam que algo deve ser cumprido na maior medida possível, de acordo com as possibilidades fáticas (o caso concreto) e jurídicas (determinadas pelos princípios e regras colidentes). Nessa esteira, o grau de importância atribuído a um princípio no caso concreto será dado de acordo com as possibilidades fáticas e jurídicas, em que o grau de satisfação de um importará em menor grau de satisfação de outro, sem que ambos percam sua validade. Por isso, os princípios podem ser cumpridos em diferentes graus (ALEXY, 1997, p. 90) ${ }^{10}$.

Em caso de conflito entre princípios, deve haver um procedimento racional para sua resolução, que Alexy (2003, p. 5) denominou de ponderação. Ao responder às críticas de Habermas sobre a técnica do balanceamento, Alexy afirmou que este é parte de um princípio mais abrangente: o da proporcionalidade, que consiste em três princípios: adequação,

\footnotetext{
${ }^{8}$ Aqui se faz interessante uma observação: para os “casos fáceis”, a aplicação do direito continua sendo realizada como sempre foi, ao passo que nos denominados "casos difíceis" - hard cases, justificar-se-ia a utilização de fundamentos morais, políticos e exteriores ao direito, convocados por meio da argumentação. Cf. SIMIONI, 2014, p. 239.

${ }_{9}$ Em Dworkin os princípios não estão necessariamente positivados, já que advêm de nossas convicções de moralidade.

${ }^{10}$ Assim, em caso de eventual colisão, os princípios devem ser aplicados por um procedimento denominado de ponderação que só pode ser realizada no âmbito de uma argumentação jurídica (SIMIONI, 2014, p. 272).
} 
necessidade e proporcionalidade em sentido estrito, sendo que todos dão a ideia de otimização. Os dois primeiros dizem respeito às possibilidades fáticas, enquanto o último às jurídicas ${ }^{11}$.

Não obstante a teoria de Alexy ter tido grande aceitação em território nacional, não ficou isenta de críticas tanto por autores brasileiros quanto estrangeiros, destacando-se, por todos, Lenio Streck (2014a) e Habermas (2001). Streck (2014a, p. 556) destaca o fato de que para se fazer a distinção estrutural operada por Alexy é necessário estar diante de um conceito semântico prévio de norma, de modo que a obrigatoriedade dos princípios não decorre dessa operação. Isso porque a palavra norma representa o produto da interpretação de um texto (norma é evento), que vai se dar pela aplicação de uma regra (orientada por um princípio instituidor). Se estamos certos de que a norma não existe sem interpretação e que esta não se faz sem um caso concreto, não poderá haver um conceito prévio ao caso concreto (STRECK, 2014a, p. 557).

Há também em Streck críticas atinentes à abertura principiológica. Em Alexy (1997, passim), enquanto os princípios são normas que apresentam conteúdo generalizante (abstrato) e as regras possuem conteúdo menos generalizante (fechado), em Streck (2014a, p. 570) é justamente o contrário: os princípios fecham a interpretação, já que toda aplicação de uma regra será feita a partir de seu princípio instituidor (é a regra que abre a interpretação, já que pretende abarcar todos os casos). Por fim, a ponderação também permite arbitrariedade ao intérprete: afinal, quem atribuirá o peso ao princípio?

Por outro lado, as críticas de Habermas (2001, p. 332) podem ser sintetizadas em dois aspectos: i) ao equiparar princípios a valores, há um esvaziamento do seu conteúdo deontológico, porquanto os direitos são elevados a fins e objetivos; ii) a ponderação subtrai as decisões do domínio da justificação para o da correção, isto é, ela produz um juízo de resultado que não se articula com as alternativas de uma decisão correta ou incorreta.

Apesar das críticas a Alexy, este é um dos autores que mais influenciam o direito pátrio, estando sua teoria da ponderação presente em importantes decisões do STF, a exemplo da possibilidade de execução provisória da pena proferida no julgamento do Habeas Corpus n. 175.626/SP.

\footnotetext{
${ }^{11}$ De início, consigna-se que após as críticas de Habermas, Alexy mudou a forma de apresentação de sua teoria, não obstante ocorresse apenas uma mudança no modo de sua apresentação (apresentando, para tanto, as condições de precedência e a fórmula peso). A referida metodologia pode ser apresentada didaticamente: primeiro, identificam-se os princípios em colisão; segundo, comprovam-se os graus de não satisfação de um diante da satisfação de outro; terceiro, comprova-se a importância da satisfação de todos no caso concreto; quarto, apresentam-se os motivos que justificam a consideração da importância de um; quinto, indicação das consequências de um maior peso para um em detrimento de outro. Cf. SIMIONI, 2014, p. 292.
} 


\section{O MÉTODO DA PONDERAÇÃO VERSUS A QUESTÃO DO PESO: DISTINÇÕES NECESSÁRIAS ENTRE DWORKIN E ALEXY}

Tendo em vista que o objetivo deste artigo é a problematização do conceito de princípios para, a partir disso, lançar luzes no modo como tal questão se manifesta na prática jurídica, chegou a hora de confrontarmos brevemente as duas posições daqueles que mais se debruçaram a respeito do conceito e do papel dos princípios, no caso, Ronald Dworkin e Robert Alexy.

Dworkin vê a discricionariedade como um grande problema do positivismo jurídico, notadamente nos casos "difíceis", já que - caso não haja uma resposta em uma regra - ao juiz é dado o poder de criar direito novo. Por sua vez, Alexy realiza uma tentativa de conciliar o positivismo normativo de Kelsen com o jusnaturalismo material de Radbruch por meio de um procedimento que permita com que uma decisão seja proferida racionalmente, o que torna necessário traçar alguns pontos que distingam tais concepções, para que não se caia no agulhão teórico de utilizar as duas concepções como se fossem sinônimas.

De início, viu-se que tanto em Dworkin como em Alexy as regras se aplicam no âmbito do tudo ou nada, isto é, ou são válidas ou são inválidas, sendo que sua aplicação se dá no âmbito da subsunção. Todavia, Alexy parte de uma concepção que vê os princípios como mandados de otimização que podem ser cumpridos na maior medida possível, de acordo com as possibilidades fáticas e jurídicas, ao passo que as regras seriam mandados de definição. Esse caráter dos princípios implica na necessidade da ponderação, que é a sua forma de aplicação, enquanto a forma de aplicação das regras seria a subsunção.

No entanto, em Alexy os princípios se manifestam em um caráter lógico previamente delimitado, enquanto em Dworkin a normatividade dos princípios se manifesta argumentativamente no interior dessa atividade interpretativa que é o direito, o que faz com que sua delimitação do conceito de princípio se distancie de Alexy. Além disso, ao se referir à dimensão de peso ou importância, os princípios passam a ter um caráter transcendental que nos remete à ideia de totalidade na qual estamos inseridos (OLIVEIRA, 2008, p. 173).

Outrossim, o conceito de princípio em Alexy não diz nada a respeito da fundamentalidade da norma (SILVA, 2003, p. 613), já que é determinado levando em conta sua estrutura normativa. Dito de outro modo, um princípio pode ser uma "norma fundamental de um sistema" como também não ser. Ao contrário, em Dworkin, é o grau de importância (peso) 
que determinará os princípios, na medida em que são os padrões de moralidade política que justificam nossas práticas.

Além disso, o método da ponderação faz com que haja uma legitimação da decisão judicial pelo procedimento, já que, caso as três etapas - adequação, necessidade e proporcionalidade em sentido estrito - sejam cumpridas, a decisão é legitima. Assim, enquanto para Alexy há uma teoria semântica da norma jurídica, em Dworkin há uma teoria pragmática que parte da ideia de que o direito é uma prática interpretativa, de sorte que uma decisão estará justificada quando obedeça a coerência e a integridade dos princípios que compõem a história institucional da comunidade, o que faz com que cada caso apresente um problema de equidade, pois gera um compromisso de se levar a história da comunidade em consideração no próximo julgamento e, caso o romance em cadeia seja rompido, há a necessidade de justificação por argumentos de princípios ainda maiores.

\section{OS PRINCÍPIOS GERAIS DO DIREITO $\mathrm{E}$ A NECESSIDADE DE SUA SUPERAÇÃO}

Conforme explicitado, um dos problemas centrais do positivismo de Hart surgiria nos “casos difíceis", em que os juízes não encontrariam uma resposta ao caso concreto com base em uma regra. Nesse caso, em razão de haver uma lacuna legal, estaria o juiz autorizado a preenchê-la por meio da discrição judicial, ou seja, por meio de uma escolha que considere a melhor para aquele caso.

Além disso, também em Kelsen se verifica uma das principais discussões acerca das lacunas, classificadas como ficções (KELSEN, 2012, p. 344). Para ele, tal fato decorre não de uma omissão legal, e sim porque a decisão logicamente possível aparece ao aplicador como inoportuna ou injusta e, por isso, "este se inclina a admitir que o legislador não previu estecaso, sendo que, se efetivamente o tivesse previsto, por certo teria tomado decisão diferenteda que resulta do Direito vigente (STRECK, 2014b, p. 154)”. Daí porque haveria uma divergência entre direito positivo e o outro direito considerado melhor ou justo (STRECK, 2014b, p. 154).

O ordenamento jurídico pátrio previu, no art. $4^{\circ}$ da Lei de Introdução das Normas do Direito Brasileiro (LINDB), que, quando a lei for omissa, o juiz decidirá de acordo com a analogia, os costumes e os princípios gerais do direito, e o art. $3^{\circ}$ do Código de Processo Penal aduziu que a lei processual permitirá o suprimento pelos princípios gerais do direito. Nesse sentido, afirma Maria Helena Diniz que: 
Quando a analogia e o costume falham no preenchimento da lacuna, o magistrado supre a deficiência da ordem jurídica, adotando princípios gerais do direito, que são cânones que não foram ditados, explicitamente, pelo elaborador da norma, mas que estão contidos de forma imanente no ordenamento jurídico (DINIZ, 2012, p. 44).

Diz ainda, "São normas de valor genérico que orientam a compreensão do sistema jurídico, em sua aplicação e integração, estejam ou não positivados” (DINIZ, 2012, p. 96). Como exemplo, Maria Helena Diniz (DINIZ, 2012, p. 95) cita a moralidade administrativa (art. $5^{\circ}, \mathrm{LXXIII} \mathrm{c/c} \mathrm{37,} \mathrm{caput,} \mathrm{CRFB/88} \mathrm{c/c} \mathrm{art.} \mathrm{85,} \mathrm{CRFB/88);} \mathrm{a} \mathrm{igualdade} \mathrm{de} \mathrm{direitos} \mathrm{e} \mathrm{deveres} \mathrm{(art.}$ $5^{\circ}$, caput, CRFB/88); a função social da propriedade (art. $5^{\circ}$, XXIII, 182 e $\S 2^{\circ}, 184$ e 185 , parágrafo único, e 186 da CRFB/88), dentre outros.

Mas qual a diferença dos citados "princípios gerais do direito" para os princípios propriamente ditos? Seriam a mesma coisa? Ou os princípios seriam uma decorrência lógica dos princípios gerais do direito? É evidente que todos aqueles que utilizam o direito em sua cotidianidade têm uma noção vaga do que seja um princípio, mas a pergunta acerca de seu papel e de seu real significado permanece encoberta. Rafael Thomas de Oliveira (2008, p. 31) menciona três significados distintos que podem ser dados ao conceito de princípio: a) princípios gerais do direito; b) princípios jurídico-epistemológicos; c) princípios pragmáticosproblemáticos, que Streck (2017, p. 239) prefere nomear de princípios constitucionais. Isso porque, dependendo da função que se reivindica, o termo princípio pode ser utilizado em âmbitos muito diferentes de denotação.

Para que se possam entender os princípios gerais do direito, faz-se necessário, inicialmente, compreender o jusnaturalismo racionalista e seu projeto de construção do direito pela razão. Os projetos de codificação oitocentistas representavam tal projeto (OLIVEIRA, 2008, p 32), de forma a possibilitar a superação do dogmatismo teleológico medieval ao apresentar o homem racional como legislador de si próprio. Nesse aspecto, os princípios gerais do direito aparecem como "reminiscências do projeto jusnaturalista em pleno seio da cultura positivista emergente, como figuras capazes de suprimir as eventuais lacunas existentes no sistema positivado do direito para preservar a completude lógico-sistemática conquistada racionalmente" (OLIVEIRA, 2008, p. 33).

Assim, os princípios gerais do direito são impregnados por uma aposta em um mundo paralelo: eles chegam ao ordenamento com a finalidade de solucionar os problemas advindos da insuficiência do modelo exegético (juiz boca da lei) e passam a ser um meio pelo qual o juiz pode decidir naqueles casos em que a solução do caso concreto não encontra resposta em uma lei precisa. 
Como observa Streck (2014b, p. 166), enquanto os princípios gerais do direito representam uma autorização para a discricionariedade, já que o juiz não encontrava uma resposta no sistema codificado, os princípios constitucionais se apresentam como uma contraposição à referida discricionariedade. Na medida em que não existem princípios sem regras nem regras sem princípios, a diferença entre ambos é que estes estão contidos naquelas. Eles, pois, trazem “à tona o sentido que resulta desse ponto de encontro entre texto e realidade, em que um não subsiste sem o outro (STRECK, 2014b, p. 167)”. O conceito de princípios jurídico-epistemológicos, por sua vez, está relacionado à consolidação do Estado Liberal e à radicação do estatalismo do século XIX, podendo ser descritos em dois níveis correlatos: a) em um ramo específico do direito (penal, administrativo, etc); b) em projetos epistemológicos, como é o caso da Teoria Pura do Direito de Kelsen (OLIVEIRA, 2008, p. 36). Eles são epistemológicos pela pretensão de organizar o estudo de determinada disciplina, distinguindose dos princípios gerais do direito pelo fato de que não têm a finalidade de suprir lacunas existentes do sistema, mas sim de possibilitar, de modo coerente, o conhecimento de certa disciplina.

Na Teoria Pura do Direito, com o fim de descrever o direito como uma ciência positiva, sem recurso a argumentos morais ou políticos, Kelsen descreve a ordem normativa por um elemento organizador do mundo jurídico, no caso, o princípio da imputação que rege as leis jurídicas, em contraposição ao da causalidade, que diz respeito às leis naturais. Enquanto a proposição jurídica é produzida por meio de uma norma estabelecida por uma autoridade jurídica por meio de um ato de vontade, a lei natural independente de qualquer intervenção dessa espécie (KELSEN, 2009, p. 86).

Em outro giro, o conceito de princípios pragmáticos ou problemáticos é sugerido por Esser (1961, p. 62) ao se referir à concretude de aplicação do direito em face da abstração sistemática. Isso o distancia das concepções anteriores, na medida em que a questão se desloca do elemento abstrato-sistemático para a atividade concreta do juiz, que "deixa de ter o caráter de uma simples atividade de dedução de conceitos - parte da estrutura sistemática da ordem jurídica - e passa a ser colocada na necessidade de justificação judicial" (STRECK, 2017, p. 241). Distinguem-se, conforme Castanheira Neves (2003, p. 108), dos princípios gerais do direito que o positivismo via como axioma jurídico-racional de seu sistema jurídico, porquanto agora são princípios "normativamente materiais fundantes da própria juridicidade, expressões normativas de 'o direito' em que o sistema jurídico cobra o seu sentido e não apenas a sua racionalidade (NEVES, 2003, p. 108)". 
Dessa forma, a partir dos significados que podem ser atribuídos aos princípios, é possível estabelecer o campo em que se está trabalhando, de sorte que se conclui que os princípios (jurídicos) não são álibis teóricos que visam suprir a insuficiência das regras (princípios gerais do direito), devendo ser entendidos por meio de uma ruptura paradigmática, isto é, como a instituição do mundo prático no direito que passa a representar o elevado grau de autonomia que este passou a ter, notadamente no paradigma do segundo pós-guerra.

\section{O PROBLEMA DA PROLIFERAÇÃO DOS PRINCÍPIOS: O PANPRINCIPIOLOGISMO E O ENFRAQUECIMENTO DA AUTONOMIA DO DIREITO}

O que pode ser verificado como decorrência da não compreensão do papel dos princípios (constitucionais) como sucedâneos dos princípios gerais do direito é a proliferação dos mais variados princípios que não apresentam tal característica, isto é, caso feita uma rigorosa verificação, não contribuem para a obtenção de respostas adequadas à Constituição e que atribuam legitimidade à aplicação de um preceito jurídico, já que os princípios demarcam o caminho legítimo de aplicação das regras.

Além disso, a ideia de que os princípios abrem a interpretação - já que apresentam alto grau de abstração e generalidade - contribui para o enfraquecimento da autonomia do direito, uma vez que qualquer resposta passa a ser adequada, pois basta ao magistrado lançar mão de um dos variados princípios criados $a d$ hoc para que a decisão seja correta ${ }^{12}$.

O tema relativo à proliferação dos princípios não é recente, ganhando destaque os estudos realizados por Streck (2014a, p. 524 e ss.), que elenca quase 40 "princípios" utilizados na prática forense: a grande maioria deles não passaria por uma filtragem constitucional. Nesse diapasão, em tese de doutorado, Letícia Ritter (2016, p. 119), tendo por recorte teórico os livros de Direito Processual Civil, verificou a existência de 157 princípios devidamente conceituados.

Além de Streck, Luigi Ferrajoli (2012, p. 47), em trabalho realizado em coautoria com Streck e outros, denomina a profusão de princípios como "bolha terminológica", notadamente por entendê-la como uma das consequências do neoconstitucionalismo, a que o autor chama de constitucionalismo argumentativo.

12 Rafael Thomas de Oliveira (2008, passim) também advoga que o uso indiscriminado do termo princípio dificulta a conceituação do que seja princípio. 
Assim, a criação de tantos princípios

Pode acarretar o enfraquecimento da autonomia do direito (e da força normativa da Constituição), na medida em que parcela considerável (desses “princípios”) é transformada em discursos com pretensões de correção [...] caminho perigoso para um retorno à "completude" que caracterizou o velho positivismo novecentista, mas que adentrou ao século XX: na "ausência" de "leis apropriadas" [...] o intérprete "deve" lançar mão dessa ampla principiologia, sendo que, na falta de um "princípio" aplicável, o próprio intérprete pode criá-lo (STRECK, 2014a, p. 545).

Nesse aspecto, citem-se como exemplo os denominados "princípios" do livre convencimento motivado, da verdade real, da confiança do juiz na causa - que tem sido utilizado para o não provimento de recursos - do ativismo judicial, dentre outros, os quais possuem nítidas pretensões de correção. Destaca-se, por oportuno, este último "princípio" aplicável ao Processo Coletivo, sobre o qual autores do porte de Fredie Didier (2010, p. 124) chegam a dizer, "são expressões deste princípio a atuação do juiz no controle das políticas públicas, os poderes de flexibilização procedimental e o aumento dos poderes instrutórios do juiz".

O problema do uso indiscriminado dos princípios pode gerar grave insegurança jurídica e enfraquecimento da autonomia do direito, já que qualquer resposta passa a ser possível, uma vez que os recursos podem ser julgados improcedentes pelo argumento de que o juiz de primeira instância está mais próximo dos fatos e, por isso, a apelação será improvida (isto é, o princípio da confiança do juiz na causapode ser utilizado tanto para condenar quanto para absolver). Do mesmo modo que se permite, com base na verdade real, a aplicação do art. 156, inciso I, do CPP, dando ao juiz a prerrogativa de determinar provas de ofício mesmo que na fase do inquérito policial, em clara violação ao sistema acusatório.

Desse modo, é necessária uma reflexão crítica do modo como os referidos "princípios" vêm sendo utilizados em alguns julgados, uma vez que permitem alto grau de subjetividade ao julgador. Além disso, o que determina os princípios são as vivências fáticas, uma vez que toda carga principiológica será formada a partir da ideia de comum-unidade. A "resposta adequada à Constituição" será auferida na medida em que o preceito esteja legitimado pela aplicação do princípio (constitucional) que o institui. 


\section{OS PRINCÍPIOS NA CRÍTICA HERMENÊUTICA DO DIREITO DE LENIO STRECK: A INTRODUÇÃO DO MUNDO PRÁTICO NO DIREITO}

A discricionariedade é um ponto presente tanto na Teoria Pura de Kelsen quanto no Conceito de Direito de Hart, já que, enquanto no primeiro o intérprete teria a prerrogativa de proceder à escolha de um dos sentidos jurídicos da norma, no segundo haveria, nos casos difíceis, a possibilidade de o aplicador do direito atuar por meio da discrição judicial, já que quando não há uma regra aplicável diretamente ao caso concreto o juiz pode criar direito novo.

Além disso, percebeu-se também em Alexy que os princípios permitem uma abertura interpretativa, uma vez que ele aceita a tese da abertura textual do direito de Hart e Kelsen, haja vista que um de seus problemas centrais foi o de explorar essa dimensão, a qual seria a porta de entrada - no interior do discurso jurídico - "para elementos morais ou questões de justiça presentes naquilo que ele chama de discurso prático geral"' (STRECK, 2014a, p. 382).

A persistência, ainda, de parcela da doutrina civilista (Cf. DINIZ, 2012) em apontar diversos princípios (constitucionais) como sinônimos dos princípios gerais do direito, bem como a indeterminação do conceito dos princípios - e de seu papel - têm contribuído para o enfraquecimento da autonomia do direito e para a profusão desenfreada de "princípios" que permite que qualquer decisão jurídica possa ser "correta" (constitucionalmente adequada ou, melhor dizendo, em consonância com a Constituição), já que estaria justificada por um "princípio".

Por conseguinte, considerando que os princípios representam o elevado grau de legitimidade que o direito assumiu, mormente no paradigma do Estado Democrático de Direito e que podem contribuir para a redução do grau de discricionariedade dos magistrados (por dizerem o caminho legítimo de aplicação de uma regra), pretende-se lançar luzes sobre o conceito de princípio e seu papel a partir dos aportes teóricos da Crítica Hermenêutica do Direito. Nessa perspectiva, a partir da Filosofia Hermenêutica de Heidegger e da Hermenêutica Filosófica de Gadamer, bem como da teoria integrativa de Dworkin, a Crítica se situa dentro do giro ontológico-linguístico provocado pela Filosofia, isto é, em um contexto históricolinguístico em que o sujeito se vê imerso, que fornece e molda um horizonte de sentido, em que a linguagem aparece como condição de possibilidade para a própria constituição do conhecimento (GADAMER, 2001, p. 452).

A partir dessas imbricações, a Crítica Hermenêutica do Direito visa a superar os dualismos "existentes" entre: compreender, interpretar e aplicar; sujeito e objeto; casos fác eis 
e casos difíceis; questões de fato e questões de direito, para citar apenas algumas. Ademais, o grande dilema contemporâneo é o de construir as condições necessárias para que a jurisdição constitucional não se sobreponha ao próprio direito, na medida em que o direito não deve ser e nem é aquilo que os Tribunais dizem que ele é (STRECK, 2009, p. 13).

Em Streck (2014a, p. 568), a diferença (e não a cisão) entre regras e princípios parte da descoberta do caráter unificador destes, que são o marco de institucionalização da autonomia do direito. Isso porque as regras não acontecem sem os princípios, que atuam como condições de possibilidade para concretização do direito. Enquanto as regras regem o caso ao apontar para o que deve e não deve ser feito, os princípios fazem com que a solução dada ao caso seja dotada de autoridade (apontam o caminho legítimo de aplicação da regra).

Quando se diz que os princípios institucionalizam o mundo prático no direito, referese à diferença ontológica ${ }^{13}$ que implica a pergunta sobre o modo como os princípios acontecem - eles se darão na abertura do ser-aí enquanto ser-no-mundo. Isso porque será através dos princípios "que o debate envolvendo o ethos, a liberdade, a interpretação e outros problemas que se relacionam mais diretamente à condição humana, são retomados pelo mundo (OLIVEIRA, 2008, p. 186)".

Tal perspectiva faz com que o conceito de princípios na Crítica Hermenêutica do Direito se distancie de um conceito semântico - definido pela abstração ou generalidade e pela colisão em abstrato - que permite um sequestro do mundo prático. Assim, a igualdade (virtude soberana) será um princípio não pelo fato de que determine que algo seja realizado na maior medida possível de acordo com as possibilidades fáticas e jurídicas, mas sim porque servirá para dizer o caminho legítimo de determinação das regras, já que, afinal, todo caso jurídico carrega em si a ideia de igualdade.

Desse modo, a legitimidade de uma decisão judicial estará auferida na medida em que demonstre que a regra por ela aplicada é instituída por um princípio (STRECK, 2014a, p. 553). As regras regem o caso, determinando o que deve ser feito, ao passo que os princípios dizem o caminho legítimo de aplicação de uma regra. Assim, se não há regra sem princípio nem princípio sem regra, há, por conseguinte, um fechamento interpretativo.

Um exemplo prático deixa essa questão mais clara. De acordo com o artigo 155 do Código Penal, aquele que subtrai, para si ou para outrem, coisa alheia móvel, incorre no crime

\footnotetext{
${ }^{13} \mathrm{Na}$ hermenêutica heideggeriana, a hermenêutica passou a se referir não somente à interpretação de textos, mas ao pensamento e a atividade humana, buscando responder ao sentido do ser e que, não podendo ser concebido como um ente, que possui a característica da indefinibilidade (HEIDEGGER, 2006, p. 37). Nesse desiderato, é estabelecida a distinção entre ser e ente - diferença ontológica (GADAMER, 2007, p. 92).
} 
de furto. Ao se aplicar a regra sem um princípio que a institucionaliza, estaríamos permitindo que subtrações sem violência de objetos insignificantes fossem punidas pelo Direito Penal. Assim, a subtração de um pote de manteiga por alguém seria considerado furto.

Ocorre que, ao se aplicar a diferença ontológica à distinção entre princípios e regras, percebe-se que o preceito do artigo 155 do Código Penal passará a ser lido da seguinte maneira: "Subtrair, para si ou para outrem, coisa alheia móvel, desde que haja relevante lesão ao bem jurídico tutelado". Como os princípios dizem o caminho legítimo de aplicação de uma regra eles fecham a interpretação -, permite-se uma blindagem à discricionariedade judicial, pois o artigo 155 do Código Penal só será aplicado nos casos de afastamento do princípio da insignificância, porquanto não há crime sem relevante lesão ou perigo de lesão ao bem jurídico tutelado, o que faz com que haja a exclusão da tipicidade material.

Assim, a indevida distinção estrutural produzida pela teoria da argumentação jurídica de Alexy, no sentido de que as regras são aplicadas por subsunção e os princípios por ponderação, acaba por sucumbir o caráter de transcendência dos princípios, na medida em "não há regras - legítimas - que não estejam, desde logo, suportadas por princípios (OLIVEIRA, 2008, p. 212)". No fundo, quando se diz que entre regra e princípio há (apenas) uma "diferença (ontológica, no sentido da fenomenologia hermenêutica - no original, OntologischeDifferentz), é porque regra e princípio se dão, isto é, eles acontecem (na sua norma) no interior do círculo hermenêutico" (STRECK, 2014a, p. 19).

Desse modo, ao contrário da teoria argumentativa alexyana em que os princípios, devido ao seu alto grau de abstração e generalidade, apresentam uma abertura interpretativa, em Streck (2014a, p. 570) é justamente o contrário, porquanto a aplicação de uma regra será sempre guiada por seu princípio instituidor.

\section{CONSIDERAÇÕES FINAIS}

Em seis etapas, problematizamos o conceito de princípio e sua utilização na prática jurídica brasileira em um sentido transcendental (como algo que sempre acontece no mundo concreto), fato que impossibilita qualquer relação aprisionadora entre sujeito e objeto. Viu-se que o célere debate entre Hart e Dworkin teve como pano de fundo o papel dos princípios na redução dos espaços de discricionariedade judicial, de sorte que, mesmo nos casos em que não haja uma resposta na legislação, o juiz tem o dever de decidir por princípios. 
Percebeu-se também que predomina no direito brasileiro, quer na doutrina, quer na jurisprudência, a concepção de que os princípios são mandados de otimização que podem ser cumpridos em diferentes graus, e que, em caso de eventual conflito, demandarão um procedimento racional de decisão: a ponderação.No entanto, a ideia da colisão em abstrato e da abertura interpretativa dos princípios possibilita que sejam utilizados argumentos exógenos ao direito na justificação das decisões, o que faz com que haja um grande risco à autonomia do direito.

Além disso, outro aspecto peculiar refere-se à utilização do conceito de princípio, que, conforme o sentido atribuído, poderá assumir três significados distintos: a) princípios gerais do direito; b) princípios jurídico-epistemológicos; c) princípios pragmáticos-problemáticos, fato que faz perceber que os princípios constitucionais não se confundem com os princípios gerais do direito, como parcela dos civilistas parece indicar.

Nesse aspecto, aliás, reside o problema do "panprincipiologismo”, que, em razão da proliferação dos mais variados princípios no cotidiano forense, há um consequente enfraquecimento da autonomia do direito, já que na falta de um princípio aplicável o intérprete estaria autorizado a lançar mão da ampla carga principiológica.

Por outro lado, há um salto qualitativo na Crítica Hermenêutica de Streck quando introduz a diferença ontológica heideggeriana na relação entre princípios e regras. Apesar de entre eles haver uma diferença, acontecem em uma unidade que é a antecipação de sentido: não há princípios sem regras nem regras sem princípios, uma vez que estes apontam o caminho legítimo de aplicação daquelas (os princípios são transcendentais). Texto e norma não podem ser compreendidos isoladamente, na medida em que o preceito será compreendido a partir do princípio que o institui, do mesmo modo que o princípio será compreendido em sua regra.

Com efeito, os princípios, ao contrário da teoria da argumentação, operam um fechamento interpretativo, conduzindo à obtenção de respostas corretas - nem a única, nem a melhor, mas adequadas à Constituição, que somente ocorrerão quando for respeitada a coerência e a integridade do direito e a aplicação de uma regra ao caso em análise esteja justificada por um princípio (constitucional) instituidor. Isso porque os princípios (constitucionais) apresentam espaços argumentativos que permitem o controle das decisões judiciais. Eles retiram seu conteúdo normativo de uma vivência intersubjetiva emanada dos vínculos existentes na moralidade política da comunidade, sendo, pois, faticizados (vivenciados) pelos participantes da comunidade. 


\section{REFERÊNCIAS}

ALEXY, Robert. A Theory of Constitutional Rights. Trans. J. Rivers. Oxford: Oxford University Press, 2002.

Constitutional rights, balancing and rationality. Ratio Juris, v.16, n. 2, p. 131-140, 2003.Avaliablefrom: <https://is.muni.cz/el/1422/jaro2008/CM218Zk/um/3479707/Alexy__Balancing.pdf $>$. Acessed in: Aug. 8th, 2018. 1997.

Teoria de los derechos fundamentales. Madrid: Centro de Etudios Constitucionales,

ÁVILA, Humberto. Teoria dos Princípios: da definição à aplicação dos princípios jurídicos.

8. Ed. São Paulo: Editora Malheiros, 2008.

CANOTILHO, José Joaquim Gomes. Direito Constitucional e Teoria da Constituição. 4.ed. Coimbra: Almedina, 1992.

DIDIER JR, Fredie. Curso de direito processual civil: introdução ao direito processual civil, parte geral e processo de conhecimento. 17. ed. Salvador: Editora Juspodivm, 2015.

ZANETI JR, Hermes. Curso de direito processual civil: processo coletivo. v. 4. 5. ed. Salvador: Editora Juspodivm, 2010.

DINIZ, Maria Helena. Curso de direito civil brasileiro, volume 1: teoria geral do direito civil. 29. ed. São Paulo: Saraiva, 2012.

DWORKIN, Ronald. A justiça de Toga. São Paulo: WMF Martins Fontes, 2010.

Levando os Direitos a Sério. São Paulo: Martins Fontes, 2002.

ESSER, Josef. Principio y Norma em la Elaboración Jurisprudencial del Derecho Privado. Tradução de Eduardo ValentíFiol. Barcelona: Bosch, 1961.

FERRAJOLI, Luigi. Constitucionalismo principialista e constitucionalismo garantista. In: FERRAJOLI, Luigi; STRECK, Lenio Luis; TRINDADE, André Karam (orgs). Garantismo, hermenêutica e (neo)constitucionalismo: um debate com Luigi Ferrajoli. Porto Alegre: Livraria do Advogado, 2012.

GADAMER, Hans-Georg. Hermenêutica em Retrospectiva: Heidegger em retrospectiva. 2. ed. Petrópolis/RJ: Vozes, 2007.

Verdade e método I: traços fundamentais de uma hermenêutica filosófica. Trad. Flávio Paulo Meurer. Petrópolis: Vozes, 2001.

HABERMAS, Jürgen. Factidad y validez: sobre el derecho y el Estado democrático de derecho em términos de teoria del discurso. Trad. Manuel Jiménez Redondo. Madrid: Trotta, 2001.

HART, H. L. A. O conceito de direito. São Paulo: WMF Martins Fontes, 2009. 
HEIDEGGER, Martin. Ser e Tempo, Parte I. 15. Ed. Trad. Marcia Sã Cavalcante Schuback. Editora Vozes, 2006.

KELSEN, Hans. Teoria pura do direito. 8. ed. São Paulo: Martins Fontes, 2012.

LOPES JR, Aury. Direito processual penal. 11. Ed. São Paulo: Saraiva, 2014.

MORAIS, Fausto Santos de. Hermenêutica e pretensão de correção: uma revisão crítica da aplicação da proporcionalidade pelo Supremo Tribunal Federal. Tese (doutorado). Universidade do Vale do Rio dos Sinos - Programa de Pós-Graduação em Direito. São Leopoldo: UNISINOS, 2013.

MOTTA, Francisco José Borges. Ronald Dworkin e a decisão jurídica. Salvador: Editora Juspodivm, 2017.

NEVES, A. Castanheira. A crise actual da filosofia do direito no contexto da crise global da filosofia:tópicos para a possibilidade de uma reflexiva reabilitação. Coimbra: Universidade de Coimbra, 2003.

OLIVEIRA, Rafael Thomas de. Decisão Judicial e o Conceito de Princípio: a hermenêutica e a (in)determinação do Direito. Porto Alegre: Livraria do Advogado, 2008.

RITTER, Letícia Mousquer. O papel do juiz no Estado Democrático de Direito: perspectivas epistemológicas da função judicial no século XXI. Tese (doutorado) - Universidade do Vale do Rio dos Sinos, Programa de Pós-Graduação em Direito, 2016.

SHAPIRO, Scott J. The "Hart-Dworkin" Debate. A Short Guide for the Perplexed. The Social Science Research. Network Electronic Paper Collection, 2007. Disponível em: $<$ https://law.yale.edu/system/files/documents/pdf/Faculty/Shapiro_Hart_Dworkin_Debate.pdf >. Acesso em: 08/08/2018.

SILVA, Virgílio Afonso da. Princípios e regras: mitos e equívocos acerca de uma distinção. Revista Latino-Americana de Estudos Constitucionais 1, 2003: 307-630. Disponível em: $<$ https://constituicao.direito.usp.br/wp-content/uploads/2003-RLAEC01Principios_e_regras.pdf>. Acesso em: 08/08/2018.

SIMIONI, Rafael Lazzarotto. Curso de hermenêutica jurídica contemporânea: do positivismo clássico ao pós-positivismo jurídico. Curitiba: Juruá, 2014.

STRECK, Lenio Luiz. Ainda e sempre o problema da relação "princípio-regra": uma análise em tempos pós-positivistas. LEITE, George Salomão; SARLET, Ingo Wolfgang (Orgs). Jurisdição Constitucional, Democracia e Direitos Fundamentais. Salvador: Editora Juspodivm, 2013.

Dicionário de hermenêutica: quarenta temas fundamentais da teoria do direito à luz da crítica hermenêutica do Direito. Belo Horizonte: Letramento: Casa do Direito, 2017.

Hermenêutica Jurídica e(m) crise: $u$ ma exploração hermenêutica da construção do Direito. 11. ed. Porto Alegre: Livraria do Advogado, 2014b. 
Hermenêutica, Neoconstitucionalismo e "O Problema da Discricionariedade dos

Juízes". Anima - revista eletrônica do curso de Direito da OPET, Curitiba, 1 ed., v. 1, p. 383 413. 2009.

Neoconstitucionalismo, positivismo e pós-positivismo. In: FERRAJOLI, Luigi; STRECK, Lenio Luis; TRINDADE, André Karam (orgs). Garantismo, hermenêutica e (neo)constitucionalismo: um debate com Luigi Ferrajoli. Porto Alegre: Livraria do Advogado, 2012. 2014a.

Verdade e Consenso: Constituição, Hermenêutica e Teorias Discursivas. Saraiva,

Trabalho recebido em 10 de junho de 2020

Aceito em 23 de Agosto de 2021 